\title{
A comparative study of Negative Psycho- Social factors in Working and Non-Working Elderly Persons
}

\author{
${ }^{1}$ Shefali Singh, ${ }^{2}$ Dr. Jyoti Gaur, \\ ${ }^{1,2}$ The IIS University, Jaipur
}

\begin{abstract}
Psychosocial means it relates to one's psychological development in, and interaction with, a social environment. The present research is focussed on A comparative study of Negative Psycho-Social factors in Working and Non-Working Elderly Persons of age 60-80 years of Jaipur city. The tool is designed by Ms. Savina Bishnoi (2012). The tool consist 65 items those divided into 13 dimensions which measures the psycho-social characteristics of Elderly people in different areas regarding self-esteem, pertaining to cognitive capacity, meaningful roles in ourselves and others life, physically deterioration, social relations and social contacts with friends and relatives, about financial condition and resources, different moods like Loneliness, insecurity, dependency physically and mentally, about how much capable of caring a chronically ill person, health status, social support from spouse, friends and family, life events of individual life.. The sampling population of this research includes 80 Elderly persons living in Jaipur out of which 40 are Working and 40 are Non Working. The sample was collected by simple random sampling method. The population belonging to age group of 60-80 years was taken in study. The result revealed that There is significant difference between the psycho social factors scores of Working and Non-Working Elderly
\end{abstract}

Key words:

\section{Introduction}

Elderly consists of ages nearing or surpassing the average life span of human beings, and thus the end of the human life cycle. Terms for old people include seniors, senior citizens ,older adults , and the Elderly..Old people often have limited regenerative abilities and are more prone to disease, syndromes, and sickness than younger adults. The medical study of the aging process is gerontology, and the study of diseases that afflict the Elderly is Geriatrics.

The boundary between Middle age and Elderly cannot be defined exactly because it does not have the same meaning in all societies. People can be considered old because of certain changes in their activities or social roles. Examples: people may be considered old when they become grandparents, or when they begin to do less or different work-retirement. Most countries have accepted the chronological age of 65 years as a definition of 'Elderly' or older person.

Psychosocial means it relates to one's psychological development in, and interaction with, a social environment. The individual needs not be fully aware of this relationship with his or her environment. It was first commonly used by psychologist Erik Erickson in his stages of social development.

The rapid growth in the number of very old people raises questions about the quality of additional years of life lived by those achieving exceptional longevity. The World Health Organization has declared that "increased longevity without quality of life is an empty prize" ${ }^{[11]}$ However, aging is a multidimensional concept, and psychosocial factors that assess psychological and social well-being should be included in conceptual frameworks used to understand the aging process ${ }^{[2] . ~ G e r o n t o l o g i s t s ~ h a v e ~ b e e n ~ i n t e r e s t e d ~ i n ~ t h e ~ p s y c h o s o c i a l ~}$ dimensions of quality of life in older adults for some time. In his conceptualization of the "good life", Lawton argued that psychosocial indicators of well-being are inextricably linked with health and functioning in determining quality of life among older adults ${ }^{[9]}$.

Psychosocial dimensions of well-being, such as social relationships, feelings of loneliness, and satisfaction with life, are important factors to consider in the measurement of quality of life among older adults [9,1]. Illness increases with age. All else being equal, an older population has greater needs for health care. Most developed world countries have accepted the chronological age of 65 years as a definition of 'Elderly' or older person, but like many westernized concepts, this does not adapt well to the situation in Africa. Although there are commonly used definitions of Elderly, there is no general agreement on the age at which a person becomes old. (WHO)

\section{Changes associated with aging} other things:

There is often a general physical decline, and people become less active. Elderly can cause, amongst 
- Wrinkles and liver spots on the skin due to loss of subcutaneous fat

- Change of hair color to gray or white

- Hair loss

- Reduced circulatory system function and blood flow

- Reduced lung capacity

- Reduced immune system function

- Changes in the vocal cords that produce the typical "old person" voice

- Heightened risk for injury from falls that otherwise would not cause injury

- Lessened and weakened hearing.

- Diminished eyesight. It becomes more difficult to read in low lighting and in smaller print. Speed with which an individual reads may also be impaired.

- $\quad$ Reduced mental and cognitive ability.

- Depressed mood.

- Lessening or cessation of sex, sometimes because of physical symptoms such as erectile dysfunction in men, but often simply a decline in libido.

- Greater susceptibility to bone and joint diseases such as osteoarthritis and osteoporosis

- Memory loss is common due to the decrease in speed of information being encoded, stored, and received. It may take more time to learn new information.

- Alzheimer's disease, the most common form of dementia, is found in Elderly. It is a general term for memory loss and other intellectual abilities serious enough to interfere with daily life. Behavioral changes can include wandering, physical aggression, and verbal outbursts due to diseases such as depression, psychosis, or dementia.

In most parts of the world, women live, on average, longer than men. Therefore life expectancy of females is more as compared to men. Accidents and disease claimed many people before they could attain Elderly, and because health problems over 65 meant a quick death in most cases. If a person lived to an advanced age, it was due to genetic factors and/or a relatively easy lifestyle. There is concern, for instance, that those who survive to very Elderly spend their remaining years in a state of poor health and functioning and, therefore, have a poor quality of life ${ }^{[4,5]}$ Research on long-lived individuals indeed confirms that among individuals who survive to exceptional Elderly there is a high prevalence of disease and disability as well as

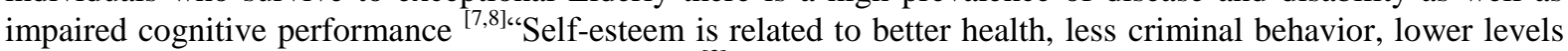
of depression and, overall, greater success in life".

\section{Objective}

Going through the literature and keeping in mind the stereotyped views towards the elderly, it is necessary to study the factors contributing to their personality. Hence research has been planned and conducted to compare the general feelings, social relationships, loneliness, self esteem, life expectancy, cognitive abilities of the Working and Non-Working Elderly persons, with the following objectives in view-

To find out the Negative Psychosocial factors in between working and Non-Working Elderly people.

To find out the differences in the various dimensions in the Negative Psychosocial factors of working and NonWorking Elderly people.

\section{Hypothesis}

$\left.\mathrm{H}_{0} 1\right)$ There is no significant difference between the Negative Psychosocial factors in working and NonWorking Elderly people.

$\mathrm{H}_{0} 2$ ) There is no significant difference between the Negative Psychosocial factors in working males and working females.

$\mathrm{H}_{0} 3$ ) There is no significant difference between the Negative Psychosocial factors in Non-Working males and Non-Working females.

$\left.\mathrm{H}_{0} 4\right)$ There is no significant difference between the Negative Psychosocial factors in working males and Non-Working males

$\left.\mathrm{H}_{0} 5\right)$ There is no significant difference between the Negative Psychosocial factors in working females and Non-Working females.

$\mathrm{H}_{0} 6$ ) There is no significant difference between the various dimensions of Negative Psychosocial factors in working and Non-Working Elderly persons 
Sample

\section{Research Methodology}

The population selected for this particular study is the Working and Non-Working Elderly persons of age group 60-80 years of Jaipur city.

\section{Sampling Technique}

The sampling population of this research includes 80 Elderly persons living in Jaipur out of which 40 are Working and 40 are Non Working. The sample was collected by simple random sampling method. The population belonging to age group of 60-80 years was taken in study.

Tool

The tool is designed by Ms. Savina Bishnoi (2012). The tool consist 65 items those divided into 13 dimensions which measures the psycho-social characteristics of Elderly people in different areas regarding selfesteem, pertaining to cognitive capacity, meaningful roles in ourselves and others life, physically deterioration, social relations and social contacts with friends and relatives, about financial condition and resources, different moods like Loneliness, insecurity, dependency physically and mentally, about how much capable of caring a chronically ill person, health status, social support from spouse, friends and family, life events of individual life.

\section{Method of scoring}

From the beginning the item no. 1 to 55 and from 61 to 65 scoring pattern is $4,3,2,1,0$ and the scoring pattern of the item no. 56 to 60 is reversed that is $0,1,2,3,4$

\section{Dimensions of Psycho-Social Scale}

\begin{tabular}{|l|l|l|l|}
\hline S no. & Dimensions & Questions & Maximum Scoring \\
\hline 1. & Self Esteem & $1-5$ & 20 \\
\hline 2. & Cognitive Capacity & $6-10$ & 20 \\
\hline 3. & Meaningful Roles & $11-15$ & 20 \\
\hline 4. & Physical Deterioration & $16-20$ & 20 \\
\hline 5. & Social Contacts & $21-25$ & 20 \\
\hline 6. & Financial Resources & $26-30$ & 20 \\
\hline 7. & Insecurity & $31-35$ & 20 \\
\hline 8. & Dependency & $36-40$ & 20 \\
\hline 9. & Caring for a chronically ill & $41-45$ & 20 \\
\hline 10. & Health Status & $46-50$ & 20 \\
\hline 11. & Loneliness & $51-55$ & 20 \\
\hline 12. & Social Support & $56-60$ & 20 \\
\hline 13. & Life Events & $61-65$ & 20 \\
\hline
\end{tabular}

\section{Statistical analysis}

The gathered was tabulated, computed and analyzed using mean, SD and t test.

\section{Results and Discussions}

$\mathrm{H}_{\mathrm{O}} 1$ - There is no significant difference between the negative psychosocial factors in Working and Non-Working Elderly.

Table 1

Negative Psycho- social factors scores of Working and Non-Working Elderly

\begin{tabular}{|l|l|l|l|l|l|}
\hline Group & N & Mean & S. D & t value & Significance \\
\hline Working Elderly & 40 & 177.7 & 55.4646 & \multirow{2}{*}{ 2.2404 } & Significant \\
\hline Non -Working Elderly & 40 & 150.875 & 51.5589 & & \\
\hline
\end{tabular}


Graph 1

Negative Psycho- Social Factors scores of Working and Non-Working Elderly
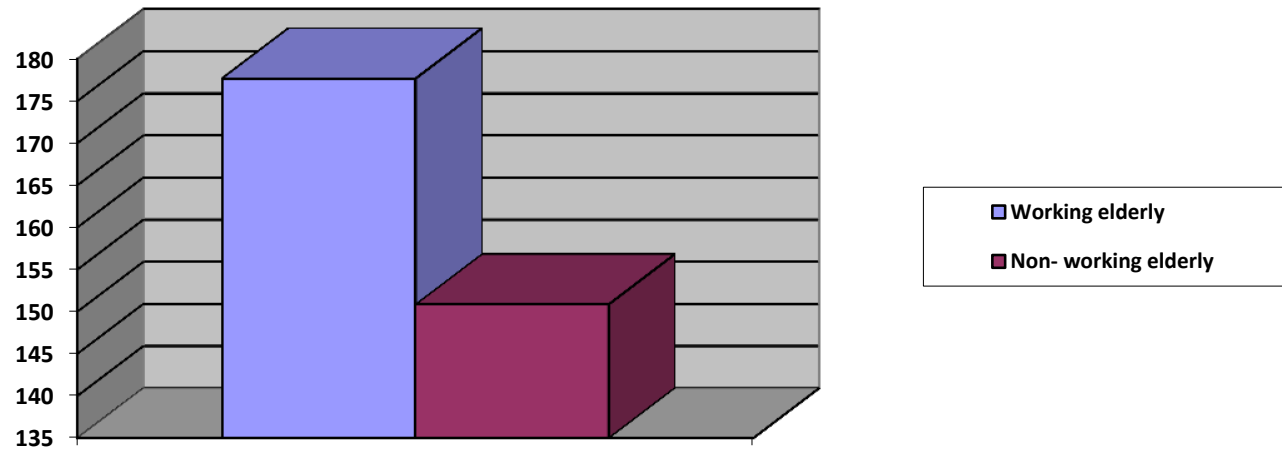

The mean scores of negative psychosocial factors of working lies in higher and non working in medium category. The two-tailed $\mathrm{P}$ value is 0.0279 which indicates that there is significant difference between the psycho social factors scores of Working and Non-Working Elderly at $95 \%$ confidence interval. This mean of the Working Elders have high degree of Psychosocial factors in comparison to Non working Elders.

The Working persons have variety of work to do. Also they tend to drop trivial subjects and divert from the negative episodes happening in their environment. On the other hand, Non-Working people's lives revolve around home, house hold chores, relations and their social circle. This difference keeps the Working persons away from the stress laid by the environment, while the Non-Working people are more critical of their immediate environment.

The result is supported by the study that shows that Females who are Working and married, are low on anxiety with higher life satisfaction in comparison to the non-Working married Females. They perceived their life as challenging and secure. They feel comfortable with their life situations. Whereas, the Non-Working married Females are less satisfied with their lives and their anxiety level is also higher than the anxiety level of Working Females ${ }^{[6]}$ Hence the hypothesis is rejected.

$\mathrm{H}_{\mathrm{O} 2}$ - There is no significant difference between the Negative psychosocial factors in Working Males and Working Females.

Table 2

Negative psycho- social factors scores of Working Females and Working Males

\begin{tabular}{|l|l|l|l|l|l|}
\hline Samples & N & Mean & S. D & t value & Significance \\
\hline Working Females & 15 & 179.867 & 64.6749 & \multirow{2}{*}{0.189} & Not significant \\
\hline Working Males & 25 & 176.4 & 50.5404 & & \\
\hline
\end{tabular}

Graph 2

Negative psycho- social factors scores of Working Females and Working Males
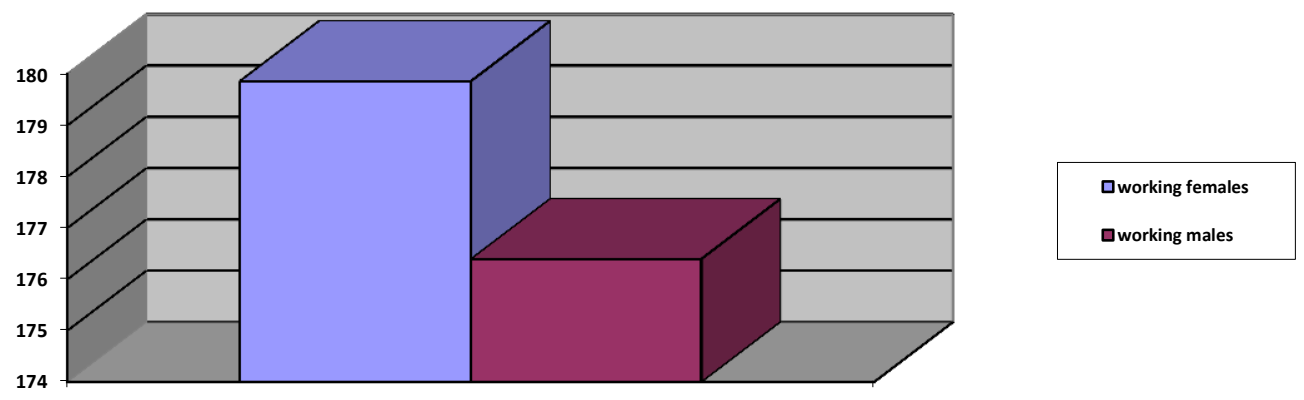

The mean scores of negative psychosocial factors in both Working Females and Working Males lies in the higher category. The two-tailed $\mathrm{P}$ value is 0.8511 which indicates that there is no statistically significant difference between the psycho social factors scores of Elderly Working Females and Males at $95 \%$ confidence interval. This concludes that both of the categories has higher degree of psychosocial well being. 
The result is supported by this study-Mars-Venus sex differences appear to be as mythical as the Man in the Moon. A 2005 analysis of 46 meta-analyses that were conducted during the last two decades of the 20th century underscores that men and women are basically alike in terms of personality, cognitive ability and leadership. Psychologist Janet Shibley Hyde, PhD, of the University of Wisconsin in Madison, discovered that males and females from childhood to adulthood are more alike than different on most psychological variables, resulting in what she calls a gender similarities hypothesis [10]. Thus hypothesis is accepted.

$\mathrm{H}_{\mathrm{O} 3}$ - There is no significant difference between the Negative Psychosocial factors in Non-Working Males and Non-Working Females.

Table 3

Negative Psycho- social factors scores of Non-Working Females and Non-Working Males

\begin{tabular}{|l|l|l|l|l|l|}
\hline Samples & N & Mean & S. D & t value & Significance \\
\hline Non-Working Females & 15 & 149.4 & 50.3896 & -0.0873 & Not significant \\
\hline $\begin{array}{l}\text { Non-Working } \\
\text { Males }\end{array}$ & 24 & 150.917 & 54.2329 & & \\
\hline
\end{tabular}

Graph 3

Negative Psycho- social factors scores of Non-Working Females and Non-Working Males
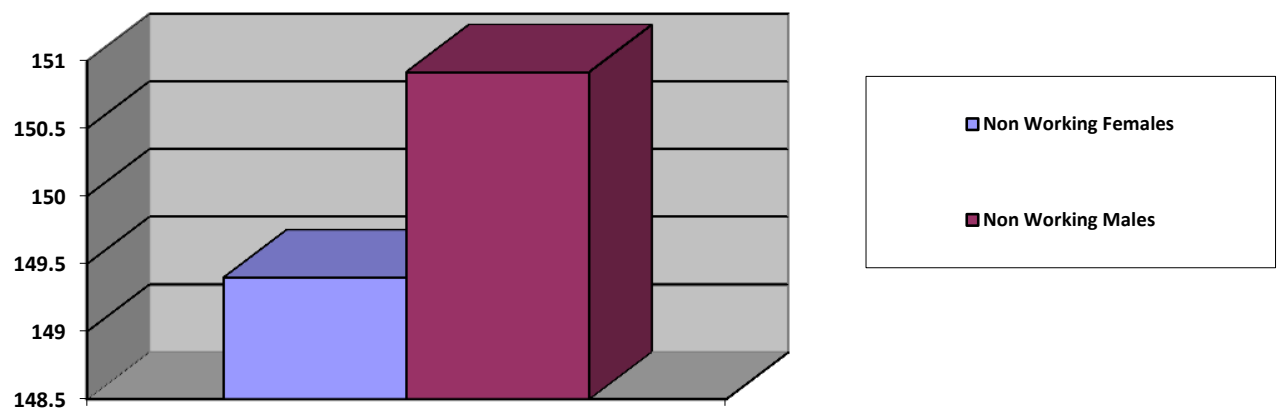

The mean scores of negative psychosocial factors lie in the medium category. The two-tailed $\mathrm{P}$ value is 0.9309 which indicates that there is no statistically significant difference between the psycho social factors scores of Elderly Non-Working Females and Males at 95\% confidence interval. Both are living in home and are free from the responsibilities of earning and don't have burden of office schedule. Other than this they also receive the relationship benefit. Thus hypothesis is accepted.

$\mathrm{H}_{\mathrm{O} 4}$ - There is no significant difference between the Negative psychosocial factors in Working Males and Non-Working Males

Table 4

Negative Psycho- social factors scores of Working Males and Non-Working Males

\begin{tabular}{|l|l|l|l|l|l|}
\hline Samples & $\mathrm{N}$ & Mean & S. D & t value & Significance \\
\hline Working Males & 25 & 176.4 & 50.5404 & \multirow{2}{*}{ Not quite significant } \\
\hline Non-Working Males & 24 & 150.917 & 54.2329 & \\
\hline
\end{tabular}


Graph 4

Negative Psycho- social factors scores of Working Males and Non-Working Males

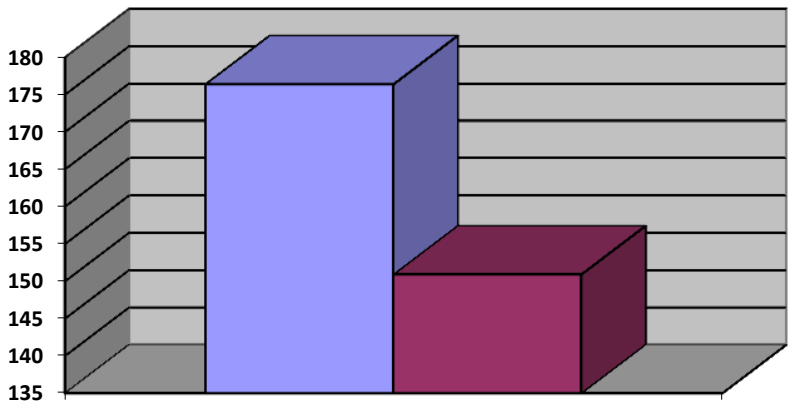

The mean scores of negative psychosocial factors lie working in high category and non working in the medium. The two-tailed $\mathrm{P}$ value is 0.0953 which indicates that there is no statistically significant difference between the psycho social factors scores of Elderly Working Males and Non-Working Males at $95 \%$ confidence interval. Although there is difference in the lifestyle of both but there is no as such difference seen in the negative psychosocial factors in Elderly Working males and Non Working males'. Thus hypothesis is accepted. $\mathrm{H}_{\mathrm{O} 5}$-There is no significant difference between the Negative psychosocial factors in Working Females and NonWorking Females.

Table 5

Negative Psycho- social factors scores of Working Females and Non-Working Females

\begin{tabular}{|l|l|l|l|l|l|l|}
\hline Samples & N & Mean & S. D & t value & Significance \\
\hline Working Females & 15 & 179.867 & 64.6749 & \multirow{2}{*}{1.4392} & Not significant \\
\hline Non-Working Females & 15 & 149.4 & 50.3896 & & \\
\hline
\end{tabular}

Graph 5

Negative Psycho- social factors scores of Working Females and Non-Working Females
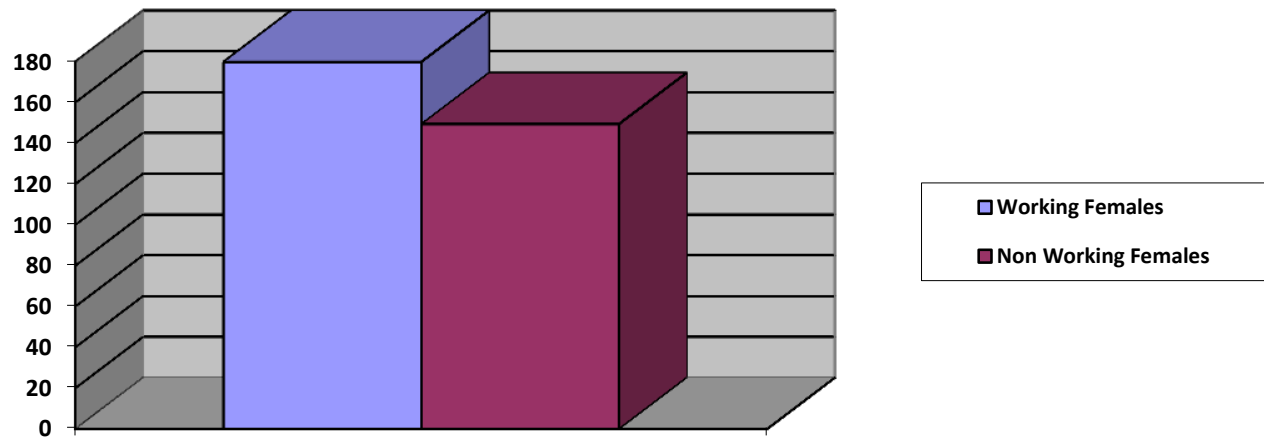

The mean scores of negative psychosocial factors lies working females in high category and Non working females in high category. The two-tailed $\mathrm{P}$ value is 0.1612 which indicates that there is no statistically significant difference between the psycho social factors scores of Elderly Working Females and Non-Working Females at $95 \%$ confidence interval. Although there is difference in the lifestyle of both but there is no as such difference seen in the negative psychosocial factors affecting in between Elderly Working and Non Working females Thus hypothesis is accepted.

$\mathrm{H}_{\mathrm{O} 6}$-There is no significant difference between the various dimensions of Negative psychosocial factors in Working and Non-Working Elderly persons 
Table 6

Various Dimension of Negative Psycho-Social Factor among Working and Non Working Elderly

\begin{tabular}{|c|c|c|c|c|c|c|c|c|}
\hline \multirow{2}{*}{$\begin{array}{l}\text { Dimension of } \\
\text { Psycho-Social } \\
\text { Factor }\end{array}$} & \multicolumn{3}{|c|}{ Working Elderly } & \multicolumn{3}{|c|}{ Non Working Elderly } & \multirow[b]{2}{*}{$\mathrm{t}$} & \multirow[b]{2}{*}{ Significance } \\
\hline & Mean & $\mathrm{N}$ & S.D & Mean & $\mathrm{N}$ & S.D & & \\
\hline Self esteem & 13.8 & 40 & 5.1451 & 10.075 & 40 & 5.0454 & 3.2693 & Very significant \\
\hline $\begin{array}{l}\text { Cognitive } \\
\text { Capacity } \\
\end{array}$ & 11.65 & 40 & 5.1168 & 9.75 & 40 & 4.8185 & 1.7097 & $\begin{array}{l}\begin{array}{l}\text { Not Quite } \\
\text { significant }\end{array} \\
\end{array}$ \\
\hline $\begin{array}{l}\text { Meaningful } \\
\text { Roles }\end{array}$ & 13.15 & 40 & 6.278 & 8.85 & 40 & 5.3424 & 3.2991 & Very Significant \\
\hline $\begin{array}{l}\text { Physical } \\
\text { Deterioration }\end{array}$ & 12.95 & 40 & 6.5475 & 9.275 & 40 & 4.2061 & 2.9867 & Significant \\
\hline $\begin{array}{l}\text { Social } \\
\text { Contacts }\end{array}$ & 12.975 & 40 & 6.0404 & 9.6 & 40 & 5.2222 & 2.6733 & Very Significant \\
\hline $\begin{array}{l}\text { Financial } \\
\text { Resources }\end{array}$ & 15.85 & 40 & 6.2943 & 12.725 & 40 & 6.9798 & 2.1029 & Significant \\
\hline Insecurity & 13.425 & 40 & 4.4715 & 11.85 & 40 & 4.8281 & 1.5137 & Not Significant \\
\hline Dependency & 14.3 & 40 & 6.3658 & 10.975 & 40 & 6.4827 & 2.3146 & Significant \\
\hline $\begin{array}{l}\text { Caring for a } \\
\text { chronically ill }\end{array}$ & 14.825 & 40 & 5.1684 & 16.475 & 40 & 3.3358 & -1.6964 & Quite significant \\
\hline Health Status & 13.85 & 40 & 5.8025 & 11.25 & 40 & 5.462 & 2.0635 & Significant \\
\hline Loneliness & 12.575 & 40 & 4.3198 & 12.05 & 40 & 5.3825 & 0.4811 & Not significant \\
\hline $\begin{array}{l}\text { Social } \\
\text { Support } \\
\end{array}$ & 14.025 & 40 & 3.7313 & 13.4 & 40 & 4.1683 & 0.7066 & Not significant \\
\hline Life Events & 14.35 & 40 & 3.4235 & 14.525 & 40 & 4.2122 & -0.2039 & Not significant \\
\hline
\end{tabular}

Graph 6

Various Dimension of Negative Psycho-Social Factor among Working and Non Working Elderly

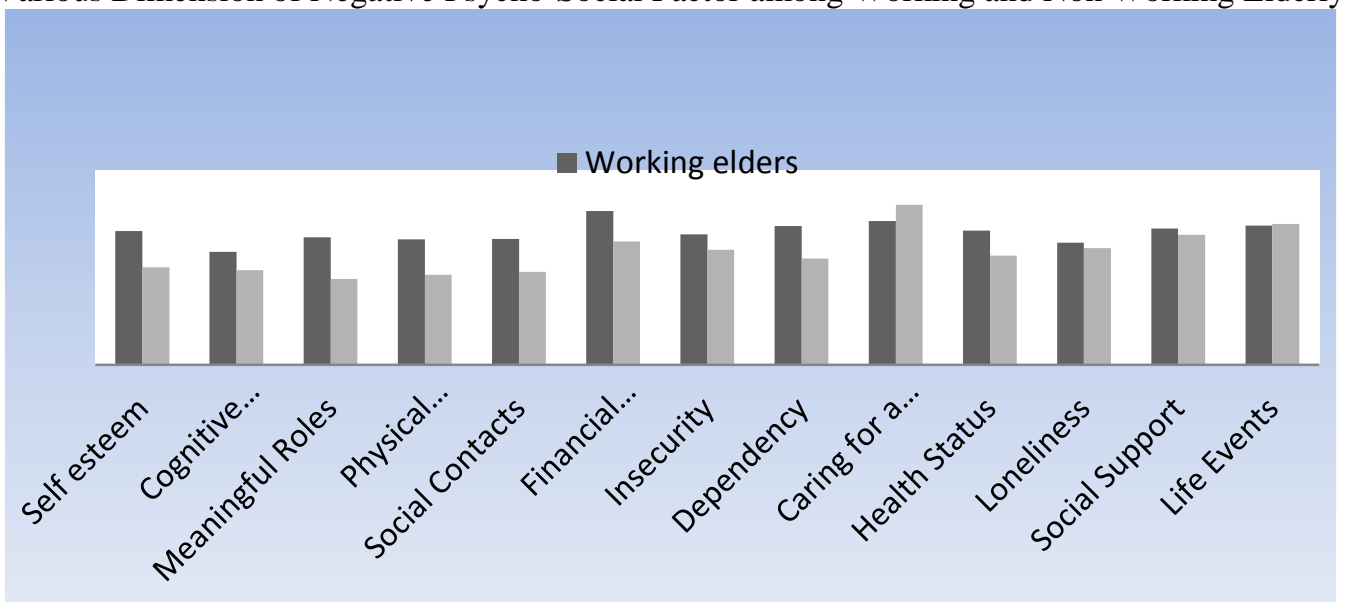

IV. Results

Indicate that there is no significant difference between the negative psychosocial factors like cognitive capabilities, loneliness, social support, and life events of working and non working elderly. Thus hypothesis is accepted.

\section{Conclusion}

- There is significant difference between the psycho social factors scores of Working and Non-Working Elderly

- There is no statistically significant difference between the psycho social factors scores of Elderly Working Females and Males

- There is no statistically significant difference between the psycho social factors scores of Elderly NonWorking Females and Males 
- There is no statistically significant difference between the psycho social factors scores of Elderly Working Males and Non-Working Males

- There is no statistically significant difference between the psycho social factors scores of Elderly Working Females and Non-Working Females

- There is no significant difference between the negative psychosocial factors like cognitive capabilities, loneliness, social support , and life events of working and non working elderly. Thus hypothesis is accepted.

\section{References and Bibliography}

[1]. B. L. Neugarten, R. J. Havighurst, and S. S. Tobin, "The measurement of life satisfaction," Journal of Gerontology, vol. 16, no. 2, pp. 134-143, 1961

[2]. C. M. Aldwin and D. F. Gilmer, Health, Illness, and Optimal Aging: Biological and Psychosocial Perspectives, Sage, Thousand Oaks, Calif, USA, 2004

[3]. Eliot R. Smith et al.Journal of Personality and Social Psychology .ISSN: 0022-3514 eISSN: 1939-1293.monthly ISI Impact Factor: 5.076 Psychology - Social: 2 of 59

[4]. E. M. Crimmins and H. Beltran-Sanchez, "Mortality and morbidity trends: is there compression of morbidity?" The Journals of Gerontology Series B, vol. 66B, no. 1, pp. 75-86, 2010.

[5]. E. M. Crimmins, M. D. Hayward, A. Hagedorn, Y. Saito, and N. Brouard, "Change in disability-free life expectancy for americans 70 years old and older," Demography, vol. 46, no. 3, pp. 627-646, 2009. View at Publisher - View at Google Scholar · View at Scopus

[6]. Irfan, M., Kaur, N., Panwar, N., Thind, H. S. (2012). A comparative study of Working and non-Working married women: Effect of Anxiety level on life satisfaction. Indian Journal of Psychology \& Mental Health, 6(2), 169-178.

[7]. J. Evert, E. Lawler, H. Bogan, and T. Perls, "Morbidity profiles of centenarians: survivors, delayers, and escapers," The Journals of Gerontology, vol. 58, no. 3, pp. 232-237, 2003. View at Scopus

[8]. K. Andersen-Ranberg, M. Schroll, and B. Jeune, "Healthy centenarians do not exist, but autonomous centenarians do: a populationbased study of morbidity among Danish centenarians," Journal of the American Geriatrics Society, vol. 49, no. 7, pp. 900-908, 2001. View at Publisher · View at Google Scholar · View at Scopus

[9]. M. P. Lawton, "Environment and other determinants of well-being in older people," The Gerontologist, vol. 23, no. 4, pp. 349-357, 1983. View at Scopus

[10]. Oliver, M. B. \& Hyde, J. S. (1993). Gender differences in sexuality: A meta-analysis. Psychological Bulletin, 114, 29-51.)

[11]. World Health Organization, The World Health Report: Report of the Director-General, World Health Organization, Geneva, Switzerland, 1997, http://www.who.int/whr/1997/en/whr97_djmessage_en.pdf/. 